\title{
Re-colonisation rate differs between co-existing indigenous and invasive intertidal mussels following major disturbance
}

\author{
Johan Erlandsson ${ }^{1,2}$, Purba Pal ${ }^{1,3}$, Christopher D. McQuaid ${ }^{1, *}$ \\ ${ }^{1}$ Department of Zoology and Entomology, Rhodes University, Grahamstown 6140, South Africa \\ ${ }^{2}$ Present address: Department of Systems Ecology, University of Stockholm, 10691 Stockholm, Sweden \\ ${ }^{3}$ Present address: Department of Invertebrate Zoology, Swedish Museum of Natural History, Box 50007, 104 05 Stockholm, Sweden
}

\begin{abstract}
The potential of introduced species to become invasive is often linked to their ability to colonise disturbed habitats rapidly. We studied the effects of major disturbance by severe storms on the indigenous mussel Perna perna and the invasive mussel Mytilus galloprovincialis in sympatric intertidal populations on the south coast of South Africa. At the study sites, these species dominate different shore levels and co-exist in the mid mussel zone. We tested the hypotheses that in the midzone P. perna would suffer less dislodgment than M. galloprovincialis, because of its greater tenacity, while $M$. galloprovincialis would respond with a higher re-colonisation rate. We estimated the percent cover of the 2 mussels in the mid-zone from photographs, once before severe storms and 3 times afterwards. M. galloprovincialis showed faster re-colonisation and 3 times more cover than $P$. perna 1 and $1.5 \mathrm{yr}$ after the storms (when populations had recovered). Storm-driven dislodgment in the midzone was highest for the species that initially dominated at each site, conforming to the concept of compensatory mortality. This resulted in similar cover of the 2 species immediately after the storms. Thus, the storm wave forces exceeded the tenacity even of $P$. perna, while the higher recruitment rate of $M$. galloprovincialis can explain its greater colonisation ability. We predict that, because of its weaker attachment strength, M. galloprovincialis will be largely excluded from open coast sites where wave action is generally stronger, but that its greater capacity for exploitation competition through re-colonisation will allow it to outcompete $P$. perna in more sheltered areas (especially in bays) that are periodically disturbed by storms.
\end{abstract}

KEY WORDS: Invasive species $\cdot$ Spatial co-existence $\cdot$ Exploitation competition $\cdot$ Mytilus $\cdot$ Perna Recovery $\cdot$ Disturbance

Resale or republication not permitted without written consent of the publisher

\section{INTRODUCTION}

Alien species have the potential to affect an ecosystem seriously by changing species diversity, community structure and interactions between organisms, sometimes causing extinction of native species (Hobbs \& Huenneke 1992, Reusch \& Williams 1999, Grosholz 2002, 2005, Castilla et al. 2004, Lee \& Klasing 2004, Hoekstra et al. 2005, Schlaepfer et al. 2005). Because shipping and hence the introduction of marine species to non-native localities have increased, coastal marine habitats have become some of the most invaded eco- systems (Grosholz 2002). A species newly introduced to a locality may become invasive if it has some of the following characteristics: a short generation time, high fecundity, a rapid growth rate, a good dispersal ability and large genetic variation (Lee \& Klasing 2004). The ways that a non-indigenous species responds (in terms of survival, reproduction and growth) to resource availability, natural enemies and the physical environment determine its ability to invade a new region or area (Shea \& Chesson 2002).

Environmental disturbance is usually assumed to release resources (e.g. space) and provide opportuni- 
ties for non-indigenous species to invade a new area (Hobbs \& Huenneke 1992, Shea \& Chesson 2002). However, theory predicts that a successful invader must still have some advantage over an indigenous species, at least at particular times or places, or in a certain life-history trait, such as colonising ability (Shea \& Chesson 2002, With 2002, Hastings et al. 2005). Differences in the response of indigenous and invasive species to variable harsh environmental factors mean that an inferior competitor for a resource could still invade an area if it were a superior coloniser (Shea \& Chesson 2002). In accordance with this reasoning, it has been suggested that invaders may be more similar to 'r-selected' species and indigenous species more similar to 'K-selected' species. McMahon (2002) reviewed North American freshwater bivalves and suggested that the indigenous species were more K-selected, giving them adaptations that provide higher resistance against environmental extremes, while invasive species may be more r-selected and have life-history strategies that would allow rapid population recovery.

Seven species of marine molluscs have been introduced to South Africa by accident (Griffiths et al. 1992). Of these species, the Mediterranean blue mussel Mytilus galloprovincialis (Lamarck, 1819) became invasive (Griffiths et al. 1992) after its introduction to the west coast of South Africa in the late 1970s (Grant \& Cherry 1985). It has since become the most abundant mussel on the west coast ( $>70 \%$ of mussel biomass), having outcompeted the indigenous mussel Aulacomya ater (Molina, 1782) because of its higher fecundity, recruitment and growth rates (van Erkom Schurink \& Griffiths 1990, 1991, 1993, Griffiths et al. 1992, Steffani \& Branch 2003a, Branch \& Steffani 2004). M. galloprovincialis has spread ca. $1000 \mathrm{~km}$ along the south coast of South Africa since 1990 (McQuaid \& Phillips 2000, Robinson et al. 2005). There it is a threat to the indigenous brown mussel Perna perna (Linnaeus, 1758), the dominant mussel on the south and east coasts, which has generally lower fecundity, recruitment and growth rates than other mytilid mussels (Lasiak \& Barnard 1995, Harris et al. 1998). While $P$. perna is infested by many different trematodes, M. galloprovincialis is free of these parasites both in one of its native regions (north of Spain) and in South Africa (Calvo-Ugarteburu \& McQuaid 1998a). Survival and competitive ability are negatively affected in infested $P$. perna, which may give parasitefree $M$. galloprovincialis a competitive advantage (Calvo-Ugarteburu \& McQuaid 1998b).

The abundance of Mytilus galloprovincialis is highly variable and site specific on the south coast. At sites where $M$. galloprovincialis is abundant, it dominates the upper mussel zone, and Perna perna dominates the lower mussel zone, with an overlap in distribution in the mid mussel zone (Bownes \& McQuaid in press). Mortality is higher for M. galloprovincialis on the low shore, both with storms and under normal wave conditions (Bownes 2005, Rius \& McQuaid 2006). Furthermore, field experiments have shown that $P$. perna has higher tenacity than $M$. galloprovincialis, because it produces more and thicker byssus threads (Zardi et al. in press). This appears to give $P$. perna higher resistance against wave disturbance. Settlement rates of $P$. perna are less consistent through the year, and, in the upper mussel zone, it suffers greater post-settlement mortality of recent recruits than $M$. galloprovincialis (Bownes 2005). These factors may explain the differences in zonation between the 2 species.

Storm waves that generate strong lift forces can have severe effects on intertidal organisms, especially in mussel beds on exposed rocky shores, where large, distinct gaps of bare space are often formed (Paine \& Levin 1981, Denny 1987). This has been observed on the west coast of North America, where Mytilus californianus (Conrad, 1837) in the later stages of succession following a disturbance by storm waves shows almost complete domination over Mytilus trossulus (Gould, 1850) in mature mussel beds (Paine \& Levin 1981, Paine 1984, Suchanek 1985). It has been suggested that $M$. californianus has a higher competitive ability than $M$. trossulus (but see also Wootton 2002) in the competition for space, which is often the limiting resource on intertidal rocky shores. Natural disturbances such as strong waves and storms are also quite frequent on South African shores, and have the potential to dislodge large areas of mussel bed on the south coast.

In the present paper, we test the model that an indigenous species (Perna perna) has higher resistance to environmental disturbance (less easily dislodged by storm waves) and an invader (Mytilus galloprovincialis) has higher colonisation ability following such disturbances.

\section{MATERIALS AND METHODS}

Study area and sampling design. We studied 2 sites where Mytilus galloprovincialis occurs at high densities on the south coast of South Africa. These sites are rather uncommon, as there are very few localities where these 2 species occur in sympatry with a high cover of $M$. galloprovincialis. The sites, Look-Out Beach and Robberg, are rocky shores separated by ca. $5 \mathrm{~km}$ in Plettenberg Bay ( $34^{\circ} 05^{\prime} \mathrm{S}, 23^{\circ} 20^{\prime} \mathrm{E}$; Fig. 1). Intertidal mussel beds in this wave-exposed region occur on the lower shore and can be divided into low, mid and upper mussel zones. The width of each mussel 


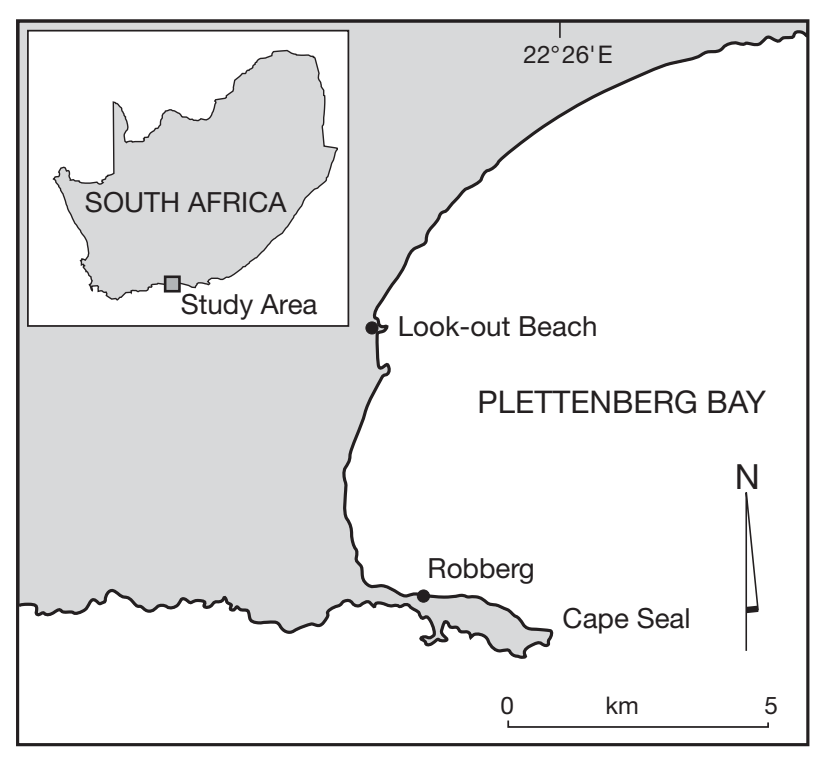

Fig. 1. Map of study area and 2 sampling sites $(\bullet)$ on the south coast of South Africa

zone depends on the slope of the shore and the degree of wave action, but generally each zone is 2 to $3 \mathrm{~m}$ wide. Mussel beds are usually monolayered, with the byssus threads of adults attached directly to the rock surface (McQuaid et al. 2000). However, in the mid-zone of Robberg some mussels are attached to other individuals, often creating more than 1 layer. At the 2 study sites, Perna perna and M. galloprovincialis overlap in distribution in the mid mussel zone, creating a patchy mosaic of the 2 species, while $P$. perna dominates the lower and $M$. galloprovincialis the upper mussel zone.

Two sub-sites, separated by ca. $25 \mathrm{~m}$, were sampled at each site. Within each sub-site, 15 non-overlapping photographs were taken haphazardly within a $5 \mathrm{~m}$ stretch in the mid mussel zone. In each photograph, the percent cover of each mussel species was estimated in a $10 \times 10 \mathrm{~cm}$ quadrat. Cover was estimated visually using a transparent frame of 16 small quadrats (each small quadrat constituting $6.25 \%$ of the total frame area) placed over the larger quadrat within the photograph. Discrimination between species was made by the following procedure: (1) we made sure that we analysed percent cover of the mussels from clear, good-quality photographs; (2) we identified the 2 mussel species mainly by shell colour, Mytilus galloprovincialis having darker and blue colours (sometimes black) and Perna perna having brown (usually light brown) and more purple colours (see Branch et al. 1994); (3) we followed the characterisation of subtle shell colour differences (e.g. narrow blue lines indicate that it is $M$. galloprovincialis) outlined by Bownes (2005) in a study of the morphology and habitat segregation between these 2 mussel species in this region.
This procedure was first performed at the end of July and the beginning of August 2000, spending $1 \mathrm{~d}$ (spring low tide) taking photographs at each site. The procedure was then repeated 3 different times (December 2000, September 2001, April 2002) to monitor the percent cover after severe storm waves removed large patches of mussels in mid-October 2000, and to monitor subsequent re-colonisation by the 2 species.

Mussels had re-colonised empty space in the mussel beds to pre-disturbance levels after about 8 mo (by May 2001), but we could not separate juveniles or recruits of the 2 species in the photographs until a few months later.

Hypotheses. The specific hypotheses for the midzone that we tested were: (1.1) storms affect Perna perna and Mytilus galloprovincialis differently, i.e. dislodgment of $P$. perna is lower than for M. galloprovincialis; (1.2) dislodgment depends on the percent cover of the 2 species before the storms, i.e. higher cover before the storms will result in higher dislodgment and lower cover just after storms; (2) re-colonisation of free space following storms occurs at a higher rate for $M$. galloprovincialis than for P. perna; (3) with different dislodgment and/or re-colonisation rates, the relative cover of the 2 species will be different after recovery from the disturbance (i.e. 1 and $1.5 \mathrm{yr}$ after the storms) compared to before the storms.

Statistical analyses. A 4-factor ANOVA was done with the percent cover of mussels in the mid-zone as the dependent variable. There were 2 fixed factors: species (2 levels-Mytilus galloprovincialis and Perna perna) and time (4 levels -2 mo before [July/August 2000], 2 mo after [December 2000]; 11 mo after [September 2001] and 18 mo after [April 2002] the storms). Thus, the different levels of the factor time represented the situation before storms, just after storms, after recovery of mussel populations and ca. 1 yr after population recovery, respectively. The remaining 2 factors were random: site (2 levels: Look-out Beach and Robberg) and sub-site (2 levels: nested in site).

Post hoc tests (Student-Neuman-Keuls [SNK]; see Underwood 1997) were also carried out for the ANOVA. The assumption of homogeneous variances was tested using Cochran's test (see below).

\section{RESULTS}

\section{Cover of Perna perna and Mytilus galloprovincialis before and after storms}

ANOVA showed a strong interaction of all 4 factors (Table 1). Variances were slightly heterogeneous (Cochran's test: $C=0.11 ; C_{\text {crit }}=0.08$; see Underwood 
Table 1. Perna perna and Mytilus galloprovincialis. A 4-factor ANOVA of the percent cover of the 2 mussels in the mid-zone. Species (Sp) and time (Ti) are fixed factors, while site (Si) and sub-site (Ss) (nested in site) are random factors

\begin{tabular}{|c|c|c|c|c|c|}
\hline $\begin{array}{l}\text { Source of } \\
\text { variation }\end{array}$ & df & MS & $F$ & $\mathrm{p}$ & $\begin{array}{l}\text { Error } \\
\text { term }\end{array}$ \\
\hline Species & 1 & 69790 & 4.49 & 0.28 & $\mathrm{Sp} \times \mathrm{Si}$ \\
\hline Time & 3 & 6508 & 6.77 & 0.08 & $\mathrm{Ti} \times \mathrm{Si}$ \\
\hline Site & 1 & 1599 & 8.21 & 0.10 & $\mathrm{Ss}(\mathrm{Si})$ \\
\hline Sub-site (Site) & 2 & 195 & 2.46 & 0.09 & Residual \\
\hline $\mathrm{Sp} \times \mathrm{Ti}$ & 3 & 15730 & 2.23 & 0.26 & $\mathrm{Sp} \times \mathrm{Ti} \times \mathrm{Si}$ \\
\hline $\mathrm{Sp} \times \mathrm{Si}$ & 1 & 15550 & 21.33 & 0.044 & $\mathrm{Sp} \times \mathrm{Ss}(\mathrm{Si})$ \\
\hline $\mathrm{Sp} \times \mathrm{Ss}(\mathrm{Si})$ & 2 & 729 & 9.21 & 0.0001 & Residual \\
\hline $\mathrm{Ti} \times \mathrm{Si}$ & 3 & 961 & 2.64 & 0.14 & $\mathrm{Ti} \times \mathrm{Ss}(\mathrm{Si})$ \\
\hline $\mathrm{Ti} \times \mathrm{Ss}(\mathrm{Si})$ & 6 & 364 & 4.60 & 0.0001 & Residual \\
\hline $\mathrm{Sp} \times \mathrm{Ti} \times \mathrm{Si}$ & 3 & 7067 & 19.45 & 0.0017 & $\mathrm{Sp} \times \mathrm{Ti} \times \mathrm{Ss}(\mathrm{Si})$ \\
\hline $\mathrm{Sp} \times \mathrm{Ti} \times \mathrm{Ss}(\mathrm{Si})$ & 6 & 363 & 4.59 & 0.0002 & Residual \\
\hline Residual & 448 & 79 & & & \\
\hline
\end{tabular}

colonised the freed space faster and by the end of the study dominated the mid-zone, with about 3 times as much cover as $P$. perna.

\section{DISCUSSION}

The present study showed that 11 mo after the storms, when populations had recovered to predisturbance levels, cover of Mytilus galloprovincialis was 3 or more times greater than that of Perna perna in the mid-zone, and the difference was even greater 7 mo later. Particularly notable was the change from $P$. perna to $M$. galloprovincialis as the species with greater cover at Look-out Beach.

We also noted that the cover of mussels was higher in the upper zone than in the midzone just after storms had occurred, even though percent cover was close to $100 \%$ in

1997, Quinn \& Keough 2002), but this could not be rectified by data transformation. However, slightly heterogeneous variances are not a problem when the numbers of different groups and degrees of freedom (df) are as high as in the present study, i.e. 32 groups and $14 \mathrm{df}$ in each (Underwood 1997, Quinn \& Keough 2002). Although sub-site was involved in significant interactions, the differences between sub-sites were relatively minor, involving the strength of effects, rather than different effects (see Fig. 2).

At Look-out Beach, Perna perna dominated the mid-zone before the storms occurred, while immediately after the storms its abundance was reduced to almost half (to the same percent cover as Mytilus galloprovincialis). Its cover then continued to decline for the following 18 mo (Fig. 2a, Table 2). In contrast, M. galloprovincialis showed low cover both before and just after the storms, but increased dramatically in abundance over the rest of the study period (Fig. 2a, Table 2).

At Robberg, the percent cover of Perna perna was rather low on all occasions, but there was no visible effect of the storms (Fig. 2b, Table 2). Mytilus galloprovincialis dominated the mid-zone at Robberg before the storms, with a decrease of more than half immediately afterwards, reaching a cover similar to that of P. perna. However, as at Look-out Beach, $M$. galloprovincialis showed rapid recovery, while $P$. perna abundance declined slightly with time (Fig. 2b, Table 2). Thus, at both sites the initially dominant species suffered drastic losses during the storms and cover of both species converged on approximately 20 to $30 \%$ in its immediate aftermath. Hence, the storms most strongly affected the species that had highest initial cover, but at both sites $M$. galloprovincialis re- both mussel zones before the storms, especially at Robberg (authors' pers. obs.). This difference may be because mussels in the mid-zone often form more than 1 layer at Robberg, so that mussels may not be attached directly to the substratum and so are easier to dislodge. In the mid-zone, the storms affected primarily the most abundant species, which differed between the sites, reducing both species at both sites to approx-

Table 2. Perna perna and Mytilus galloprovincialis. StudentNewman-Keuls test (post hoc test) of the ANOVA in Table 1, showing the sampling occasions at which the mussel cover of the 2 species differed at Look-out Beach and Robberg. Same letters indicate no significant differences between means $(p>0.05)$, while different letters show significant differences $(p<0.05)$

\begin{tabular}{|lcc|}
\hline & Date & $\begin{array}{c}\text { Homogenous } \\
\text { groups }\end{array}$ \\
\hline $\begin{array}{l}\text { Look-out Beach } \\
\text { P. perna }\end{array}$ & Aug 2000 & C \\
& Dec 2000 & b \\
& Sep 2001 & b \\
M. galloprovincialis & Apr 2002 & a \\
& Aug 2000 & b \\
& Dec 2000 & b \\
Robberg & Sep 2001 & C \\
P. perna & Apr 2002 & d \\
& Aug 2000 & b \\
& Dec 2000 & b \\
M. galloprovincialis & Sep 2001 & b \\
& Apr 2002 & a \\
& Aug 2000 & C \\
& Dec 2000 & b \\
& Sep 2001 & C \\
& Apr 2002 & C \\
\hline
\end{tabular}



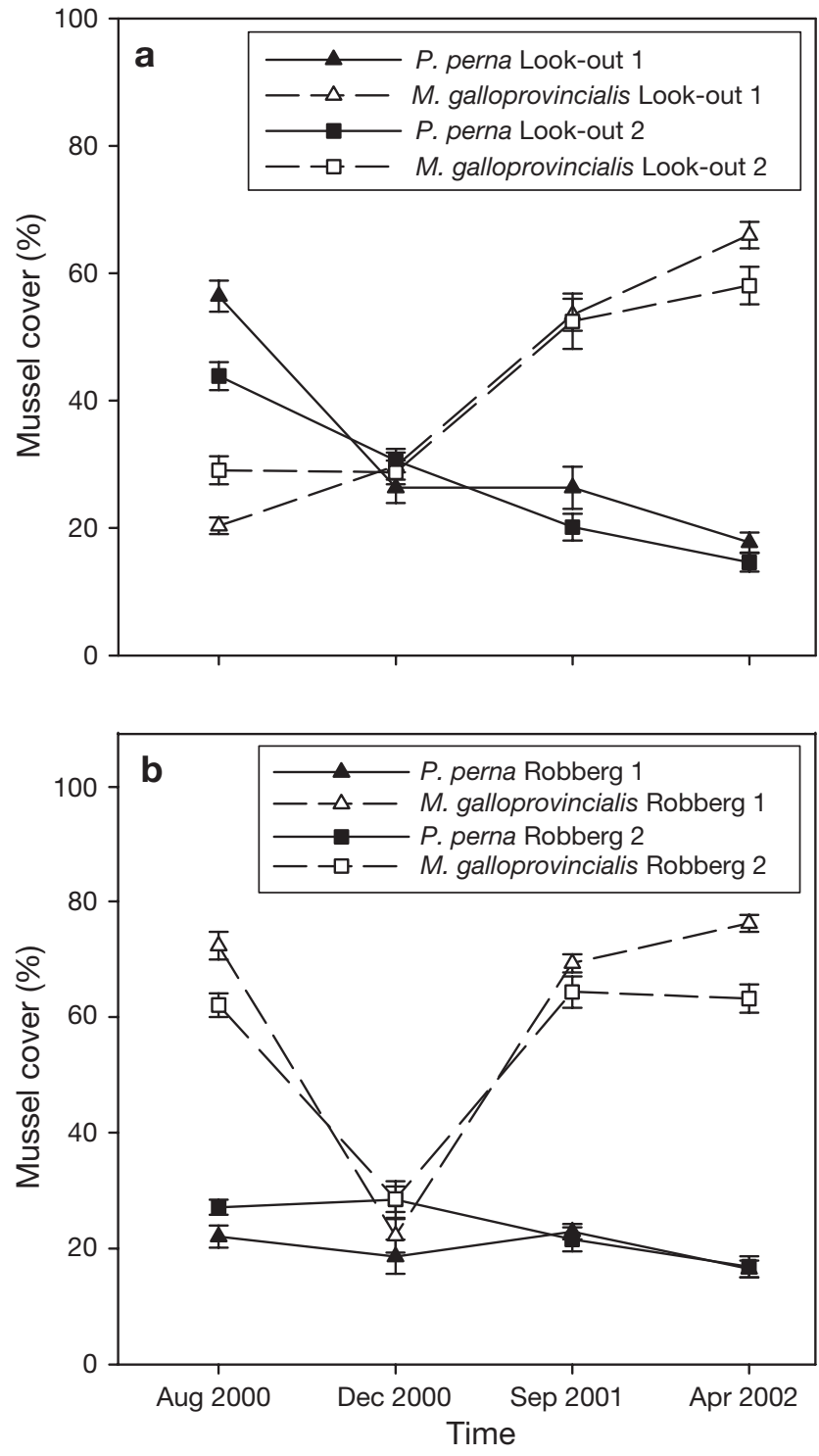

Fig. 2. Perna perna and Mytilus galloprovincialis. Mean percent cover of the 2 mussel species in the mid-zone at different times (before storms, just after storms, after recovery to pre-disturbance levels, and 7 mo later) and sub-sites at (a) Look-out Beach and (b) Robberg. Mean $\pm \mathrm{SE}$

imately $30 \%$ cover. This conforms to the concept of compensatory mortality (Connell 1978), possibly because the more abundant species is more densely packed, forming patches that are less well attached. As a result, it was straightforward to determine differences in re-colonisation rate between species.

The general model that the indigenous Perna perna would have lower dislodgment and the invasive Mytilus galloprovincialis higher re-colonisation rates was supported only regarding the prediction of differences in recovery. Hence, regardless of which species was initially more abundant at a site, the end result was the same, with $M$. galloprovincialis dominating 1 and $1.5 \mathrm{yr}$ after a major storm disturbance.

The higher re-colonisation rate and recovery of Mytilus galloprovincialis in the mid-zone following disturbance can be explained by its r-selected traits of higher fecundity, recruitment and growth rates (van Erkom Schurink \& Griffiths 1991, 1993, Lasiak \& Barnard 1995, Harris et al. 1998, Steffani \& Branch 2003a, Branch \& Steffani 2004). Settlement rates (in our definition, settlement does not encompass postsettlement mortality while recruitment does) in the Plettenberg Bay area are also generally lower and more inconsistent for Perna perna than for M. galloprovincialis (Bownes 2005), which can explain the differences in re-colonisation rates after the storms. Explaining why there were no differences in dislodgment between the 2 species is more difficult. The theory of $\mathrm{K}$ - (indigenous) and rselected (invasive) species predicts that indigenous species would have higher resistance against disturbance (McMahon 2002), and $P$. perna indeed has more byssus threads and a higher tenacity under normal wave conditions (Zardi et al. in press). There are at least 2 explanations for our results. Firstly, there may be seasonal variation in the attachment strength of mussels, e.g. the tenacity of $M$. edulis (Linnaeus, 1758) at Rhode Island increased 2 -fold in winter compared to summer (Carrington 2002). Perhaps the tenacity of $P$. perna is lower in October (when the storms occurred) than during the winter months (June to August). Mussels may also attach more strongly when predators are present, and this effect can vary both temporally and spatially in the field (see e.g. Reimer \& Tedengren 1997). Secondly, the results can be more simply explained by the strength of the storms. The waves were so strong that even the higher tenacity of $P$. perna was not sufficient to prevent dislodgment of many individuals. Thus, the effects of the storms were related more to the density (or perhaps layering) of mussels than to the tenacity of the 2 species.

Environmental disturbance may create resource opportunities for non-indigenous species (e.g. storms creating extra space), but the differences in response of indigenous and non-indigenous species determine whether or not invasion is promoted by disturbance, as is the case for some ant communities in America (Zettler et al. 2004). The spatio-temporal resource competition theory predicts that fluctuations of environmental disturbance in time and space may also have major but different effects on indigenous and nonindigenous species, favouring them at different times and places (Shea \& Chesson 2002, Hastings et al. 2005). Thus, it is possible that there was a differential temporal response in re-colonisation between Perna perna and Mytilus galloprovincialis, e.g. seasonality in 
recruitment may differ. However, recruitment of these species occurs roughly during the same seasons, and the recovery of these mussel populations took ca. $8 \mathrm{mo}$. During this period (October to May) P. perna normally has at least 1 peak in its recruitment (Harris et al. 1998, McQuaid \& Lawrie 2005). Furthermore, there was no spatial variability at local scales (within and between shores in the Plettenberg Bay area) in the differential responses (re-colonisation rate) by $P$. perna and $M$. galloprovincialis following the storms. This may, however, differ between bays and the open coast.

Intermediate disturbance or moderate frequencies of disturbance in a community can prevent competitive exclusion of organisms, thus promoting species coexistence (Connell 1978, Shea et al. 2004). For example, on rocky shore mussel beds, intermediate disturbance by storm waves or intermediate stages in the succession would promote a higher species diversity of algae, barnacles and mussels (Paine \& Levin 1981, Suchanek 1985, Sebens 1991). This co-existence may also increase competition for space between certain organisms, e.g. between Perna perna and red algae on the south-east coast of South Africa (Erlandsson et al. 2005). However, as disturbance may also affect biodiversity negatively by promoting invasions by nonindigenous species, the effects of disturbance cause a dilemma (Hobbs \& Huenneke 1992). The present study certainly shows that disturbance by severe storms can promote invasion by Mytilus galloprovincialis. The question is whether this pattern exists only on short time-scales or also on longer ones and larger spatial scales. In other words, will co-existence of $P$. perna and M. galloprovincialis be maintained on some shores of the south coast, or will M. galloprovincialis eventually displace P. perna and dominate along this coast, as it has done on the west coast? The answer to this question will depend on the strength and frequency of storms and other disturbances (e.g. mussel harvesting) in the future.

Organisms with high colonisation rates following disturbances can be successful invaders, even if they are weaker competitors (Shea \& Chesson 2002), i.e. they may be successful at exploitation competition, if not at interference competition. Mytilus galloprovincialis appears to have both a high competitive ability, e.g. due to its growth dynamics (Griffiths et al. 1992) and lack of parasites (Calvo-Ugarteburu \& McQuaid 1998a,b), and a high colonisation ability following disturbance (present study). This suggests that M. galloprovincialis will come to dominate and perhaps form mono-cultures (at the expense of Perna perna) on the shores of the south coast, as it has on the west coast of South Africa, or as $M$. californianus has on the west coast of North America (Paine 1984). However, the situation is not simple. Experimental evidence from the lower, mid and upper mussel zones of the open coast indicates that artificially created monospecific patches of M. galloprovincialis suffer $100 \%$ mortality due to normal wave action (i.e. not storms). M. galloprovincialis in mixed patches with $P$. perna show much better survival than those in monospecific patches, but still suffer mortality due to interspecific competition (Rius \& McQuaid 2006). Thus, the results of interactions between these 2 species may be site specific. For example, only some sites along the south coast have relatively high cover of $M$. galloprovincialis, and it appears to be more abundant in bays than on the open coast (C. D. McQuaid pers. obs.). On the west coast, M. galloprovincialis has higher growth and recruitment on semi-exposed shores (Steffani \& Branch 2003a, Branch \& Steffani 2004), which may suggest why there is much interaction between $M$. galloprovincialis and $P$. perna in large bays, such as Plettenberg Bay. For example, interactions between P. perna and $M$. galloprovincialis are likely to be influenced by conditions of wave action, as is the case for interactions between M. galloprovincialis and the limpet Scutellastra argenvillei (Krauss, 1848) described by Steffani \& Branch $(2003 \mathrm{a}, \mathrm{b})$. It is also possible that M. galloprovincialis has a higher re-colonisation rate than $P$. perna on bare space, but that $P$. perna will recover its population density by recruiting onto $M$. galloprovincialis patches after some time has passed. It is common for some benthic organisms to avoid colonising bare space and instead settle onto established colonies of particular species (Dunstan \& Johnson 2004). To our knowledge, there has been no observation of $P$. perna naturally re-colonising a cleared area where it is otherwise dominant; instead this results in algae and barnacles taking over the empty habitat (Hockey \& Bosman 1986). In fact, the vast majority of $P$. perna recruits are found either among algae or among adult mussels (Erlandsson \& McQuaid 2004, McQuaid \& Lindsay 2005), so that colonisation of free space is likely to be by encroachment rather than settlement.

Advantages to invaders can arise through disruption of the historical pattern of resource supply and consumption, often created by anthropogenic disturbances such as alteration of fire patterns, harvesting of biomass, nutrient enrichment, habitat destruction and climate change (Shea \& Chesson 2002). Indigenous species may not be adapted to the changed environmental conditions, which could provide resource opportunities for non-indigenous species and enhance their invasion success (Byers 2002, Shea \& Chesson 2002). For example, the frequency of severe storms and strong waves may increase in the future as a result of global warming. In the South African context, disturbances, such as the exploitation of mussels as food, as well as storms, are very common on the south and east 
coasts (Harris et al. 1998, Erlandsson \& McQuaid 2004), and increased intensity and frequency of these disturbances could favour Mytilus galloprovincialis rather than Perna perna in the colonisation of rocky shores.

Acknowledgements. We are grateful to Assoc. Profs. H. Pavia and L. B. Pettersson for constructive comments on the manuscript. This work was funded by post-doctoral fellowships (to J.E.) from the Hellmuth Hertz Foundation, Sweden, The Royal Swedish Academy of Sciences, STINT Foundation and Rhodes University, South Africa. We also thank M. Tedengren and 2 anonymous referees for constructive comments on the original manuscript.

\section{LITERATURE CITED}

Bownes SJ (2005) Habitat segregation in competing species of intertidal mussels in South Africa. PhD thesis, Rhodes University, Grahamstown

Bownes SJ, McQuaid CD (in press) Will the invasive mussel Mytilus galloprovincialis Lamarck replace the indigenous Perna perna L. on the south coast of South Africa? J Exp Mar Biol Ecol

Branch GM, Steffani CN (2004) Can we predict the effects of alien species? A case-history of the invasion of South Africa by Mytilus galloprovincialis (Lamarck). J Exp Mar Biol Ecol 300:189-215

Branch GM, Griffiths CL, Branch ML, Beckley LE (1994) Two oceans: a guide to the marine life of southern Africa. David Philip Publishers, Cape Town

Byers JE (2002) Impact of non-indigenous species on natives enhanced by anthropogenic alteration of selection regimes. Oikos 97(3):449-458

Calvo-Ugarteburu G, McQuaid CD (1998a) Parasitism and introduced species: epidemiology of trematodes in the intertidal mussels Perna perna and Mytilus galloprovincialis. J Exp Mar Biol Ecol 220:47-65

Calvo-Ugarteburu G, McQuaid CD (1998b) Parasitism and invasive species: effects of digenetic trematodes on mussels. Mar Ecol Prog Ser 169:149-163

Carrington E (2002) Seasonal variation in the attachment strength of blue mussels: causes and consequences. Limnol Oceanogr 47(6):1723-1733

Castilla JC, Guinez R, Caro AU, Ortiz V (2004) Invasion of a rocky intertidal shore by the tunicate Pyura praeputialis in the Bay of Antofagasta, Chile. Proc Natl Acad Sci USA 101(23):8517-8524

Connell JH (1978) Diversity in tropical rain forests and coral reefs. Science 199:1302-1310

Denny MW (1987) Lift as a mechanism of patch initiation in mussel beds. J Exp Mar Biol Ecol 113:231-245

Dunstan PK, Johnson CR (2004) Invasion rates increase with species richness in a marine epibenthic community by two mechanisms. Oecologia 138(2):285-292

Erlandsson J, McQuaid CD (2004) Spatial structure of recruitment in the mussel Perna perna at local scales: effects of adults, algae and recruit size. Mar Ecol Prog Ser 267: 173-185

Erlandsson J, McQuaid CD, Kostylev VE (2005) Contrasting spatial heterogeneity of sessile organisms within mussel (Perna perna) beds in relation to topographic variability. J Exp Mar Biol Ecol 314:79-97

Grant WS, Cherry MI (1985) Mytilus galloprovincialis Lmk. in southern Africa. J Exp Mar Biol Ecol 90:179-191
Griffiths CL, Hockey PAR, van Erkom Schurink C, Roux PJL (1992) Marine invasive aliens on South African shores: implications for community structure and trophic functioning. S Afr J Mar Sci 12:713-722

Grosholz ED (2002) Ecological and evolutionary consequences of coastal invasions. Trends Ecol Evol 17(1):22-27

Grosholz ED (2005) Recent biological invasion may hasten invasional meltdown by accelerating historical introductions. Proc Natl Acad Sci USA 102(4):1088-1091

Harris JM, Branch GM, Elliott BL, Currie B, Dye A, McQuaid CD, Tomalin BJ, Velasquez C (1998) Spatial and temporal variability in recruitment of intertidal mussels around the coast of southern Africa. S Afr J Zool 33:1-11

Hastings A, Cuddington K, Davies KF, Dugaw CJ and 10 others (2005) The spatial spread of invasions: new developments in theory and evidence. Ecol Lett 8:91-101

Hobbs RJ, Huenneke LF (1992) Disturbance, diversity, and invasion: implications for conservation. Conserv Biol 6(3): 324-337

Hockey PAR, Bosman AL (1986) Man as an intertidal predator in Transkei: disturbance, community convergence and management of a natural food supply. Oikos 46:3-14

Hoekstra JM, Boucher TM, Ricketts TH, Roberts C (2005) Confronting a biome crisis: global disparities of habitat loss and protection. Ecol Lett 8:23-29

Lasiak TA, Barnard TCE (1995) Recruitment of the brown mussel Perna perna onto natural substrata: a refutation of the primary/secondary settlement hypothesis. Mar Ecol Prog Ser 120:147-153

Lee KA, Klasing KC (2004) A role for immunology in invasion biology. Trends Ecol Evol 19(10):523-529

McMahon RF (2002) Evolutionary and physiological adaptations of aquatic invasive animals: $r$ selection versus resistance. Can J Fish Aquat Sci 59:1235-1244

McQuaid CD, Lawrie SM (2005) Supply-side ecology of the brown mussel, Perna perna: an investigation of spatial and temporal variation in, and coupling between, gamete release and larval supply. Mar Biol 147:955-963

McQuaid CD, Lindsay JR (2005) Interacting effects of wave exposure, tidal height and substratum on spatial variation in densities of mussel Perna perna plantigrades. Mar Ecol Prog Ser 301:173-184

McQuaid CD, Phillips TE (2000) Limited wind-driven dispersal of intertidal mussel larvae: in situ evidence from the plankton and the spread of the invasive species Mytilus galloprovincialis in South Africa. Mar Ecol Prog Ser 201:211-220

McQuaid CD, Lindsay JR, Lindsay TL (2000) Interactive effects of wave exposure and tidal height on population structure of the mussel Perna perna. Mar Biol 137:925-932

Paine RT (1984) Ecological determinism in the competition for space. Ecology 65(5):1339-1348

Paine RT, Levin SA (1981) Intertidal landscapes: disturbance and the dynamics of pattern. Ecol Monogr 51(2):145-178

Quinn GP, Keough MJ (2002) Experimental design and data analysis for biologists. Cambridge University Press, Cambridge

Reimer O, Tedengren M (1997) Predator-induced changes in byssal attachment, aggregation and migration in the blue mussel, Mytilus edulis. Mar Freshw Behav Physiol 30: 251-266

Reusch TBH, Williams SL (1999) Macrophyte canopy structure and the success of an invasive marine bivalve. Oikos 84(3):398-416

Rius M, McQuaid CD (2006) Wave action and competitive interaction between the invasive mussel Mytilus galloprovincialis and the indigenous Perna perna in South Africa. Mar Biol. doi 10.1007/s00227-006-0322-4 
Robinson TB, Griffiths CL, McQuaid CD, Rius M (2005) Marine alien species of South Africa - status and impacts. S Afr J Mar Sci 27:297-306

Schlaepfer MA, Sherman PW, Blossey B, Runge MC (2005) Introduced species as evolutionary traps. Ecol Lett 8:241-246

Sebens KP (1991) Habitat structure and community dynamics in marine benthic systems. In: Bell SS, McCoy ED, Mushinsky HR (eds) Habitat structure: the physical arrangement of objects in space. Chapman \& Hall, London, p 211-234

Shea K, Chesson P (2002) Community ecology theory as a framework for biological invasions. Trends Ecol Evol 17(4):170-176

Shea K, Roxburgh SH, Rauschert ESJ (2004) Moving from pattern to process: coexistence mechanisms under intermediate disturbance regimes. Ecol Lett 7:491-508

Steffani CN, Branch GM (2003a) Growth rate, condition, and shell shape of Mytilus galloprovincialis: responses to wave exposure. Mar Ecol Prog Ser 246:197-209

Steffani CN, Branch GM (2003b) Temporal changes in an interaction between an indigenous limpet Scutellastra argenvillei and an alien mussel Mytilus galloprovincialis: effects of wave exposure. S Afr J Mar Sci 25:213-229

Suchanek TH (1985) Mussels and their role in structuring rocky shore communities. In: Moore PG, Seed R (eds) The ecology of rocky coasts. Columbia University Press, New York, p 70-96

Editorial responsibility: Roger Hughes (Contributing Editor), Bangor, UK
Underwood AJ (1997) Experiments in ecology: their logical design and interpretation using analysis of variance. Cambridge University Press, Cambridge

van Erkom Schurink C, Griffiths CL (1990) Marine mussels of southern Africa - their distribution patterns, standing stocks, exploitation and culture. J Shellfish Res 9:75-85

van Erkom Schurink C, Griffiths CL (1991) A comparison of reproductive cycles and reproductive output in four southern African mussel species. Mar Ecol Prog Ser 76: 123-134

van Erkom Schurink C, Griffiths CL (1993) Factors affecting relative growth in four South African mussel species. Aquaculture 109:257-273

With KA (2002) The landscape ecology of invasive spread. Conserv Biol 16(5):1192-1203

Wootton JT (2002) Mechanisms of successional dynamics: consumers and the rise and fall of species dominance. Ecol Res 17(2):249-260

Zardi GI, Nicastro KR, McQuaid CD, Rius M, Porri F (in press) Hydrodynamic stress as a determinant factor in habitat segregation between the indigenous mussel Perna perna and the invasive Mytilus galloprovincialis in South Africa. Mar Biol

Zettler JA, Taylor MD, Allen CR, Spira TP (2004) Consequences of forest clear-cuts for native and nonindigenous ants (Hymenoptera: Formicidae). Ann Entomol Soc Am $97(3): 513-518$

Submitted: June 3, 2005; Accepted: February 16, 2006

Proofs received from author(s): August 7, 2006 